\title{
Mundialización y Estados-naciones: un acercamiento conceptual
}

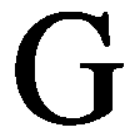
lobalización f. (Pal. ingl.) Existencia de "redes" comunicativas, económicas, culturales, publicitarias, políticas, verdes... que cubren el planeta pasando por encima de las fronteras establecidas entre países.

Probablemente el diccionario Pequeño Larousse llustrado no lo sea tanto, o sea muy viejo (es del año 1987): no contempla en su listado de palabras la que ahora nos ocupa y cuyo intento de definición hemos propuesto líneas arriba. Sirva esto, nada más, para ingresar en la consideración de un fenómeno nuevo en la historia de la humanidad que nos está locando vivir a nosolros, los liniseculares.

La complejidad del hecho mismo de la globalización exige, para abordarlo, el que nos fijemos en una perspectiva determinada, que delimitemos nuestro campo. Nos parece sugerente el acercamiento a la globalización, como tendencia creciente en nuestro mundo, en contraste con una realidad que se encuentra en crisis: el Estado-nación o, para ser más rigurosos, el sistema de naciones. Si volvemos al burdo intento de definición, encontramos allí los dos elementos claves que nos guiarán en este ensayo: aparecen bajo las palabras 'planeta' y 'países'. Según Vidal Villa, la contradicción entre la mundialización de la economía y la persistencia de los estados centrales es la más importante de nuestra época, en lo tocante al capitalismo'. Si despojamos a esa formulación de la adjetivación economicista nos quedamos con la contraposición entre muńdialización y estados-naciones.

Nos trataremos de responder, en las siguientes páginas, a la pregunta de qué entendemos por esos dos fenómenos, en un plano fundamentalmente conceplual, para apuntar al final a la comprensión de la tendencia actual de globalización.

\section{1. ¿Qué entendemos por el término 'mundialización'?}

Vamos a partir de la sustitución terminológica del anglicismo 'globalización' 
por el neologismo 'mundialización'. Justifiquemos: sin tratar de escapar de esas incontrolables corrientes del habla que moldean nuestra lengua, es decir, sin pretender que dejemos de decir 'globalización', adoptaremos, para efectos de esta exposición, la palabra 'mundialización', que consideramos equivalente. 'Global' en inglés equivale a 'mundial' en español. Como pasamos a ver inmediatamente, nuestro sustituto nos permite volver a la raíz original donde adquiere sentido el fenómeno que nos ocupa: el mundo. Arranquemos, pues, con la concepluación de mundo.

\subsection{Mundo}

La palabra mundo revela al sentido común la idea de totalidad. Se puede identificar con el globo lerráqueo, entendido como ese espacio compuesto por agua y porciones de lierra y rodeado por 'aire'. En una concepción más geopolítica, la totalidad de los países o estados nacionales. Si limitamos el término anteponiéndole un determinante posesivo - de los que antes se llamaban adjetivos posesivos-, mi mundo o tu mundo, hacemos referencia al ámbito personal de cada uno, a lo que es relevante para mí o para ti, a lo que tiene significado y es, por ello, perceptible, capaz de afectarme y moverme a la acción.

En estas nociones cotidianas existe un fondo común que desentrañaremos con la ayuda de dos teóricos.

Mead ${ }^{2 \varsigma}$ para explicar la sociedad, se detiene en un conceplo previo no específico del ser humano: el medio. A cada especie viviente le corresponde un medio, que es predeterminado por la sensibilidad de los miembros de tal especie y por su reacción ante él. Este medio no preexiste, sino se va haciendo en la interacción de especie y no especie. "La comunidad, como tal, crea su medio debido a que es sensible a él." ${ }^{33}$ En este medio vive, en el pleno sentido de la palabra, la especie; pero, en el caso de la especie humana o phylum, el medio se convierte en mundo, como señala Xavier Zubiri'. Esto porque el hombre ejerce control sobre las cosas, estas no son para él meros estímulos, son cosas reales. Mundo "es el conjunto 'respectivo' de todas las cosas reales por su 'respectividad' formal en cuanto reales, es decir, por su carácter de realidad en cuanto tal. En el mundo así entendido es en el que el hombre se tiene que mover; y por eso el mundo es siempre algo formalmente abierto. Su control humano es por esto, en buena parte, 'creación'"'.

Retomemos dos ideas claves para aterrizar en la concepción de mundo, en ese fondo común al que aludiamos más arriba. Primero, la sensibilidad específica o filélica es la que crea el medio, selecciona aquello que lo afecta y ante lo cual reacciona. Segundo, en el caso del phylum humano, esta creación es tarea abierta porque las cosas se actualizan como realidades y no como estímulos. El mundo sería una totalidad cuyas fronteras o límites son los de la misma sensibilidad humana. Aquello que pueda percibir y ante lo cual pueda reaccionar, eso 
es el mundo. ¿La luna es parte del mundo? ¿La vía láctea? Desde esta concepción, sí. No porque la luna sea habitable aún, sino por que es una 'cosa real' y 'respectiva' para el hombre. Es importante subrayar el carácter abierto del mun$d o$, pues nos hace ver que es potencialmente ampliable.

\subsection{Mundialización}

Sirvámosnos de este concepto de mundo para entrar en 'la cuestión' de la mundialización. Y si hemos escrito 'la cuestión' y no el fenómeno es porque no queremos ilusionarlos con explicaciones históricas y concretas. Apoyados en el significado $\longrightarrow$ más precisamente, en los significados — de mundo consideraremos nada más lo que significa el derivado mundialización.

Partamos del verbo 'mundializar', que tampoco aparece en el Pequeño Larousse. Pero si lo 'mundial' es lo que compete al mundo, 'mundializar' significaría 'hacer (algo) extensivo o relativo al mundo'. 'Mundialización' es la acción de 'mundializar', de extender 'algo' al mundo, es un sustantivo.

Con esta ayuda morfológica, conjuguemos los dos significados de mundo, el del sentido común y el teórico. Es el mundo, en el sentido zubiriano, de aquello en lo que el hombre -espacio, diremos- se tiene que mover, el que se extiende al mundo, en el sentido común de globo terráqueo y de sistema de naciones. Esperamos no haber caído en una tautología sin sentido. Sigamos adelante. Si bien el phylum, para seguir con esa expresión de Zubiri, ha vivido siempre en la Tierra y esta ha sido su casa, actualmente están abiertas para los hombres las puerlas que intercomunican esa casa. Esta apertura de puerlas no es nueva, como veremos cuando más adelante hagamos una breve relación historica del sistema de naciones. Pero hoy, a fines del siglo XX, se actualiza como realidad y para el colectivo el mundo como mundo. Hoy existe una sociedad mundial en el sentido de la extensión a todo el planela de los vínculos sociales ${ }^{6}$. Este mundo de hoy es creación del hombre, es un producto histórico que se ha venido generando a partir de la apropiación de posibilidades, mediante acciones como la expansión comercial y colonial, como el desarrollo tecnológico en el campo de las comunicaciones, como el agotamiento de los recursos no renovables y la destrucción del medio ambiente.

\section{2. ¿Qué entendemos por Estado-nación (o sistema de Estados-naciones)?}

El otro elemento de esta bipolaridad es el sistema de Estados nacionales y, como nos cuidamos de advertirlo, ya desde antes, es un sistema. Desde su surgimiento en Europa durante el Renacimiento, las naciones aparecen en grupo, estrechamente relacionadas unas con otras, configurándose entre sí. Adoptaremos la perspectiva del Estado-nación como unidad para esta explicación por razones tradicionales. 
El Estado nacional es una creación o artificio europeo que se va imponiendo al resto del planeta hasta cuadricularlo y no dejar fuera prácticamente ningún territorio, no dejar sin nacionalidad a ningún individuo. Todos los habitantes del planeta son potenciales portadores de un pasaporte con un escudo patrio y el nombre de su país de origen en la carátula. La forma de organización sociopolítica del Estado-nación está mundializada, extendida a todo lo ancho y largo de la Tierra.

La idea de Estado-nación es, como el término lo indica, compuesta: por un lado señala la realidad de un colectivo que comparte un espacio geográfico y una historia común; por otro, una realidad de poder o autoridad que se impone a ese colectivo.

El Estado nacional implica la afirmación de la unidad hacia adentro y la diferenciación hacia afuera.

\subsection{La nación}

Empecemos por analizar el concepto de nación. Por lo general, este concepto está cuajado de romanticismo y se le suele acompañar de mucha cursilería, no sólo por parte de políticos e ideólogos, sino también de muchos teóricos y contemporáneos. Citamos a Morin, teórico francés de CNRS, París, para ilustrar.

"Sería preciso que, al mismo tiempo, los fundamentos mitológicos/religiosos de la nación, su carácter matriopatriótico, se extendiesen, no ya solamente a escala de nuestro continente ya marcado por la civilización que él ha creado y por una comunidad de destino cada vez más evidente, sino también al conjunto de un planeta ya reconocido como única casa - home, Heimat - para la especie humana, y amenazado del mayor peligro por la propia especie humana.""

Retomemos la idea de comunidad, que aparece en el párrafo anterior, para imos introduciendo en el término que nos interesa. Comunidad es un derivado de 'común', es la unidad fundada en lo común, en lo compartido. La comunidad designada como nación hace referencia al colectivo diseminado en un territorio limitado y que comparte una misma identidad, unas actitudes, unas costumbres y unas reacciones, es decir, un vínculo similar al de sangre. Posee una conciencia nacional fundada en una historia común, en una herencia y tradición compartidas, en un sistema de símbolos - lingüísticos, religiosos-, en una cosmovisión, en un proyecto común hacia el futuro.

"Un Estado-nación es un lugar donde la gente siente un vínculo natural con los otros, por compartir un lenguaje, una religión o algo lo suficientemente fuerte para amarrarlos a todos y hacerlos sentir diferentes de los otros: 'nosotros', no 'ellos'."'

La afirmación de esa unidad hacia adentro, fundada en lo común, no puede desligarse de la diferenciación hacia afuera. La nación es impensable sin los 
otros o extranjeros; las fronteras se vuelven visibles sólo cuando son traspasadas 9 . Los otros, los de fuera, los forasteros, los bárbaros, aparecen, respecto de los naturales o nacionales en una línea común: la de la socialidad de la especie humana. Tanto 'nosotros' como 'ellos' pertenecemos a una misma especie, compartimos un esquema filético - para seguir ayudándonos de Zubiri-, tenemos en común un modo de enfrentamos con las cosas - como realidades y no como estímulos_. Formamos eso que se llama humanidad. Por eso podemos contraponernos a 'ellos' y pueden representar para nosotros una amenaza efectiva. Podemos influir en sus acciones del mismo modo que 'ellos' en las nuestras, podemos comunicarnos con ellos incluso si no hablamos, al inicio, una misma lengua. Estamos, pues, estrechamente relacionados. Nos definen, nos dicen lo que no somos y, en este sentido, formamos sistema social con ellos, estamos vinculados.

Hemos planteado lo que en teoría debería configurar las relaciones hacia adentro y hacia afuera de una nación. Pero es importante, en este momento, detenemos en el 'nosolros' con una mirada más crítica. En la realidad, los grupos con identidad común que, sin mayor discusión llamaremos 'etnias', resultan ser inferiores al colectivo que habita dentro de las fronteras de un Estado-nación. En otros términos, gran mayoría de países son multiétnicos y esle desfase aparece simultáneamente al de la conformación de los Estados nacionales. ¿Por qué, si todos pertenecemos a un mismo phylum, se nos hace tan difícil formar 'nación'? ¿Es eso de las 'etnias' algo natural que nos opone a unos frente a otros? Anticipando lo que veremos con más claridad al tratar el aspecto del Estado, esa fragmentación 'étnica' no liene otra causa que la desigualdad 'económica'l' al interior de una nación: "Cuando un grupo parece dominar el acceso a la tierra, al empleo o a los cargos públicos, entonces la característica definitoria del grupo excluido adquiere mayor importancia como base para promover la solidaridad." Esa característica definitoria o rasgo definidor puede ser de apariencia física, como el color de la piel, o bien cultural, como el tipo de vestimenta.

\subsection{El Estado}

La idea de Estado, como realidad de poder sobre una comunidad, es anterior a la formación del sistema de Estados-naciones en la Europa modema. Los griegos concebían ya al Estado como un organismo viviente, como un hombre en grande, destacando la idea de estructura sobre la de individuo. Hegel retomó esta concepción deificando al Estado como la esencia de la racionalidad, la presencia de dios en el mundo. A esta noción organicista se opone la contractualista, aparecida con los estoicos y extendida, junto a la otra, a lo largo del Medievo y la Edad Moderna. El Estado sería, desde esta perspectiva, una unidad surgida a partir de un pacto o convención aceptado por todos los miembros y cuya validez está fijada en el pacto mismo. Esta es la noción que aparece en los filósofos políticos que teorizan sobre el Estado-nación cuando ya esta. 
formación política está en marcha -aunque siempre tienen la pretensión de explicar su surgimiento-. Una concepción más reciente y más formalista sobre el Estado es la de Kelsen, que lo ve como ordenamiento jurídico y, desde ahi, define los tres elementos o propiedades características del Estado: territorio, pueblo, soberanía ${ }^{12}$. Para cerrar este breve recorrido apuntemos la noción weberiana de Estado, ya referida específicamente al Estado modemo: es la institución que, al interior de los límites de un territorio, reclama para sí el monopolio de la violencia legítima's.

\section{El Estado-nación.}

Las formulaciones teóricas acompañan a las realidades efectivas para iluminarlas o para ocultarlas, para legitimarlas o para desenmascararlas. Teniendo en cuenta las características que hemos atribuido a la nación, conjuguémosla con la noción de Estado para obtener una idea más clara del híbrido Estado-nación. Guiados por historiadores y teóricos accedamos a sus orígenes, sus funciones y su situación actual.

\subsubsection{Unes notas históricas}

Ir a los inicios del sistema de naciones significa volver la mirada hacia la Europa renacentista. Según el historiador Fernando Prieto' ${ }^{14}$ las monarquías nacionales - cuya forma política es llamada Estado modemo- son resultado de la evolución que experimentan, entre los siglos XIII y XV, las monarquías feudales y estamentales, por el impulso de la burguesía. Esta reclama un ámbito propio y protegido para su actividad económica comercial y, con el propósito de asegurárselo, fortalece el poder del monarca en detrimento del de la clase nobiliaria.

"La nueva economía demanda un poder culturalmente distinto: un poder animado por las pautas esencialmente burguesas de racionalizacion y despersonalización de las relaciones sociales, es decir, por pautas jurídicas generales o legales cuyo mantenimiento reposa en el poder de una autoridad pública que asume el monopolio del uso legítimo de la violencia."Is

Ya en la monarquía estamental, donde el rey no era absoluto, sino estaba ligado a poderes grupales o de estamentos, existe conciencia de nación, fundada en la delimitación territorial -aparecen las fronteras como tales- y en el poder de un monarca sobre lo que hay en ese territorio. Esta conciencia de nación no sería otra cosa sino el sentirse integrado a una comunidad al grado de desarrollar respecto a ella deberes de lealtad.

La integración, lo que Prieto llama principio de unidad del Estado modemo, estaría fundada en la uniformidad, en lo común, en lo compartido; sin embargo, las monarquías nacionales se organizan desde la pluralidad.

El desfase entre lo que es -pluralidad— y lo que debería ser $\rightarrow$ uniformi- 
dad-, convierte al Estado en represor o inhibidor de aquellas manifestaciones contrarias a la comunidad, a la unidad basada en lo común. Se busca imponer las manifestaciones de los grupos dominantes en orden a hacer desaparecer las diferencias, que sólo son aceptables cuando se dan entre naciones. De ahí que, desde arriba, se asigne una religión para todos los habitantes del territorio nacional, se imponga una lengua oficial, se arme a un único ejército, se establezca una administración de justicia que, por medio de funcionarios u oficiales del rey, decida sobre lo justo y lo injusto dentro de esa nación. Kennedy ${ }^{16}$ señala otros factores de unificación como el aparecimiento de una banca, una unidad monetaria y un sistema impositivo nacionales, la orientación de la producción hacia la satisfacción de las necesidades nacionales con la consiguiente disminución de las importaciones, y la reserva de los conocimientos sobre como manufacturar productos considerados propios de la nación, por ejemplo, porcelana o textiles. Sin embargo, a pesar de estos ingentes esfuerzos represores, persisten - hasta nuestros días - las diferencias hacia adentro de los Estados; casos como Cataluña y Bosnia ilustran este fenómeno.

Como señalábamos páginas atrás, esta comunidad se afirma como tal frente a otras comunidades, para lo cual es condición previa la existencia de relaciones entre ellas. Si no preexistieran lazos en un ámbito mayor que el de una determinada monarquía nacional, no sería posible la oposición entre ella y las otras como entidades con un mismo status. Los otros serían bárbaros. Las monarquías nacionales surgen en grupo y no aisladamente, se afirman como unidades que persiguen la autosuficiencia frente a instancias "universales" como el Imperio y como el Papado", frente a instituciones transnacionales como las órdenes monásticas y caballerescas y la Liga Hanseátic ${ }^{1 t} a$. A esle fenómeno Prieto lo llama el pluriverso de Estados ${ }^{\prime 9}$, expresión que subraya el carácter sistémico del conglomerado de monarquías nacionales con su consiguiente dinamismo expansivo o movilidad hacia afuera de cada una de ellas. Baste enumerar las relaciones diplomáticas entre Estados, el reconocimiento recíproco de la soberanía nacional, las guerras interestatales, la expansión colonialista como búsqueda de apéndices territoriales donde imponer el dominio, y otros movimientos supranacionales, no emanados del Estado, como las empresas comerciales y la red de comunicación entre hombres de letras para tener una idea del dinamismo.

\subsubsection{Unas notas téricas}

Atendiendo al surgimiento del sistema de naciones, nos encontramos que este nace en un mundo bastante amplio, el de una Europa interrelacionada y con vínculos hacia afuera, comerciales y coloniales. El centramiento en el Estado-nación como unidad organizadora de la vida de un colectivo constituye una opción histórica de las instancias de poder, no del "pueblo", para la consecución de sus fines, una opción "creada" a partir de las posibilidades dadas en ese momento, por tanto artificial, y cuyas consecuencias no son calculables en un inicio. 
Sin embargo, cuando los teóricos se dan a la tarea de explicarlo y justificarlo - ya el Estado nacional extendido como realidad - tienden a olvidarse de toda la trama de relaciones con el mundo circundante y lo pintan como un fenómeno cuya naturaleza es ser cerrado sobre sí mismo. El Estado, en tanto realidad de poder, surge, según pensadores políticos del siglo XVII como Thomas Hobbes y John Locke, como correlato de una sociedad, colectivo que habita en un territorio más o menos delimitado, y que por un acuerdo de todos sus miembros decide poner sobre ellos una autoridad, para que los saque del estado de guerra, en la concepción hobbesiana, o proteja sus 'propiedades', en la lockeana. Afuera del Estado-nación contemplan la existencia de otros Estados-naciones que amenazan el propio con la guerra, como señala el autor del Leviatán.

Las relaciones hacia afuera de las fronteras son concebidas como primariamente intemacionales. El sistema de naciones tiene pretensiones totalizantes, digamos mundiales: no sólo en cuanto a irse imponiendo el esquema 'Estadonación' en todas las extensiones habitadas de la Tierra, hecho que se consuma recientemente, sino también en cuanto pretende canalizar o controlar todas las relaciones que sobrepasan fronteras. Si se trata de intercambios comerciales, por ejemplo, los Estados nacionales instalan en sus fronteras aparatos de control para gravar con impuestos todo lo que ingresa a su territorio.

Volviendo al hacia adentro, la estructura del Estado-nación se ha impuesto en todo el planeta, debido a que ha resultado útil para sus miembros. Deutsch ${ }^{20}$ explica cuáles son las funciones que desempeña dicha estructura y que la vuelven de utilidad: mantiene un orden, reglas que atender, expectativas a las que atenerse; acepta la responsabilidad de responder a muchas necesidades de su pueblo; protege de las perturbaciones políticas y económicas procedentes del exterior; mantiene el status socio-económico de su pueblo - si es rico o si es pobre- frente a los demás pueblos nacionales; aumenta la movilidad social ascendente, pues ofrece más oportunidades de subir que cualquier sistema supranacional; ofrece orientación y seguridad síquicas a sus pobladores. Esto en teoría y considerando el resquebrajamiento del 'nosotros' del que hablamos más arriba.

El Estado-nación privilegia lo que está dentro en detrimento de su exterior ${ }^{21}$. Su pueblo, su nación, su gente, su sociedad, poseen, respecto de su Estado, derechos inalienables y son merecedores de respeto. Esto también aplica para el conjunto de Estados con un mismo status, los llamados palses industrializados. Los de fuera y que se encuentran en un peldaño económico inferior pertenecen a otras sociedades, son distintos y son considerados 'menos' porque la capa protectora de su Estado no los cubre tan bien como a aquellos. Este razonamiento opera, desde el inicio del Estado Modemo, hacia los que están fuera del pluriverso: los pobladores de América, África, Asia están fuera del 'mundo occidental', por ello resultan prodigiosamente colonizables, incluibles en el pluriverso como 
anexos, como siervos, porque necesitan acogerse a 'el régimen' que está a la altura de los tiempos, necesitan tener un rey, tener una lengua de verdad, profesar la verdadera religión. Necesitan estar dentro del sistema, aunque nunca lleguen a ser iguales.

El afán totalizante del sistema de naciones se puede leer en un dato que nos proporciona el sentido común: la extensión en el uso de los gentilicios y su carácter de identificar, antes que cualquier otra nota, a las personas u objetos. Sólo pensemos en el absurdo que significa para nosotros pensar en alguien -un niño, una mujer - sin nacionalidad; eso es imposible. Los gentilicios traducen origen nacional o nacionalidad, lo cual imprime -a nivel de prejuicio- determinadas 'características' al identificado. Decir que un electrodoméstico es 'americano' - gentilicio con el que los 'estadounidenses' se identifican a sí mismos- significa decir que es de buena calidad y que es costoso también, pero vale la pena, sobre todo si se compara con uno centroamericano o nacional.

\section{Los Estados-naciones y la mundialización.}

Los vínculos sociales, desde antes que iniciara la era del Estado modemo en el Renacimiento europeo, se extendían sobre amplias regiones del globo. Baste considerar realidades como el Imperio Romano, las Cruzadas, el comercio europeo con regiones orientales; esto para poner algunos ejemplos de expansión de relaciones, entendidas como el restringido cara a cara, y limitándonos a la llamada Isla de la Tierra, la porción que comprende a Europa, Asia y África. Estas redes móviles de relaciones sociales no se detuvieron al fijarse fronteras para separar un territorio de otro. Comercio, guerras, intercambio cultural, una lengua culta común, mantuvieron en relación al inicial pluriverso de Estados. Hay que agregar, para no pecar de ocultadores de vínculos como los teóricos políticos del Estado modemo, que simultáneamente al surgimiento de este sistema de naciones están ocurriendo los viajes transatlánticos que darán origen a los imperios coloniales de España, Portugal, Inglaterra. González nos previene: "Conviene no olvidar que el nacionalismo, además de ser un invento europeo, ha estado unido (no por casualidad) al comienzo de las aventuras coloniales de la era modema." 7

Mundialización y Estado-nación son dos realidades históricamente coincidentes, pero que empujan en direcciones opuestas: mientras la una tira fuertemente hacia la apertura, el otro pretende cerrarse sobre sí y convertirse en unidad de relación dentro del mundo.

Este forcejeo está cediendo en nuestro tiempo hacia el lado de lo que, no sin cierta precaución, llamaremos 'natural': la actualización del mundo como mundo. Las empresas transnacionales y los mercados financieros, los avances tecnológicos en comunicaciones y transporte, las amenazas de las armas nucleares, químicas o bacteriológicas han vuelto un verdadero mundo, un verdadero ámbito de vida para los hombres, al espacio físico mundial. 
El poder de las naciones, y con ello su razón de ser, está en crisis. Ya no pueden controlar la vida dentro de su territorio. "(El Estado nacional) ha fracasado en lo que, para John Locke y los padres fundadores de la República Americana, era la tarea más natural y básica del gobierno: la salvaguardia de las vidas de su pueblo. En caso de una guerra lotal, ningún país puede defender su capital, sus ciudades principales, y las familias de los miembros de su élite que vivan cerca de ellas." ${ }^{23}$ Cada vez menos independientes, cada vez menos autosuficientes, cada vez menos dominantes, los Estados -esos pequeños y recortados 'mundillos' - tienden a debilitarse; parece que su tiempo ha sido superado.

Siendo mundialización y Estados-naciones dos fenómenos diferentes, conviene hacer notar que ambos son 'creaciones' históricas empujadas por una misma fuerza: la lógica del capital. Ya más arriba hicimos ver como la burguesía, el capital industrial, vanguardista en el Renacimiento, movió a la conformación del pluriverso de naciones. La intensidad que ha adquirido la mundialización en nuestro tiempo, y aquí podríamos volver a emplear la palabra de los inicios, la globalización, recibe su empuje también del capilal, pero predominantemente del capital financiero que, gracias a la efectividad de las telecomunicaciones, se moviliza en un mercado mundial veinticuatro horas al día. La acumulación de capital es el vicio agente de estos fenómenos: quienes lienen capital, tienen poder de transformar el mundo apropiándose de las posibilidades de su época. Si en el siglo XV el adversario de los burgueses eran los nobles y había que superar las formaciones feudales, probablemente a fines de nuestro siglo $\mathrm{XX}$ los Estados naciones son los que obstaculizan el desarrollo expansivo de los mercados financieros y las empresas transnacionales.

Otro término de similitud entre mundialización y Estados-naciones es su carácter estructural y desigual: son composiciones de vínculos sociales donde no priva lo común, lo igual, lo compartido, sino deben ser leídos como sistemas o estructuras compuestas por múltiples elementos diversos - la unidad en la diferencia-y donde, por la lógica del capital, tienden a acentuarse las diferencias económicas -en el sentido amplio de acceso o no acceso a las cosas-. Para el caso del Estado nacional hemos señalado como este tiene la pretensión de unificar lo plural sobre lo que se asienta, sin embargo no lo consigue porque las desigualdades hacia adentro sirven al poder estatal, sirven a la lógica del capital. Esta desigualdad persiste hacia afuera y es una característica del sistema de naciones que ya nos hace ver la leoría de la dependencia ${ }^{24}$. La mundialización, en tanto fenómeno actual, se asienta sobre estas diferencias sin buscar eliminarlas: le son útiles para favorecer la acumulación en pocas manos, en las de los 'burgueses' financieros e industriales finiseculares. Sólo pensemos las razones por las que las empresas de ropa estadounidenses contratan maquilas en países latinoamericanos: porque la mano de obra aquí es más barata. Y así podríamos enumerar múltiples ejemplos que ilustraran sobre el carácter sistémico y desigual del proceso. 
Cerremos con una consideración. Si bien los Estados-nacionales tienen a la base un poder económico que, para ser tal y para fortalecerse, no puede eliminar desigualdades, tienen la pretensión de proteger a sus ciudadanos, de hacerse cargo de ellos en caso necesario. Al menos dicen sentirse responsables por ellos. Este sentido de responsabilidad social no existe en la actual mundialización, no hay - como en los Estados- pretensión de representar colectivos y luchar por sus derechos, no existe ninguna instancia que esté dispuesta a cubrir con su manto a los desprotegidos. Hace sentido en este contexto la frase del cómico mexicano Chespirito: "Y ahora, ¿quién podrá defendemos?"

\section{Notas}

1. Vidal Villa, J. M. "Diez tesis sobre la mundialización." En Arias Gómez, J. Neoliberalismo y globalización. San Salvador: Editorial Memoria, 1996, pp. 35-66.

2. Mead, G. Esptritu, persona y sociedad. Buenos Aires: Paidós, 1972, pp. 266, 269.

3. Ibid., p. 269.

4. Zubiri, X. Siere ensayos de antropología filosbfica. Bogotá: Universidad de Santo Tomás, 1982.

5. Ibid., p. 69.

6. González, A. "Orden mundial y liberación." En ECA, San Salvador, Universidad Centroamericana "José Simeón Cañas", 549, julio, 1994, p. 636.

7. Morin, E. "El Estado-nación." En Delannoi, G. y Taguieff, P. A. Teorias del nacionalismo. Barcelona: Ediciones Paidós, 1993, p. 458. El subrayado es mío.

8. "The nation-state is not yet dead." The Economist. Volumen 337, número 7946, diciembre 1995 -enero 1996, p. 15-18. La traducción de la cita, tomada de la p. 17, es mía.

9. Zalewski, M. y Enloc, C. "Questions about Identity in International Relations." En Booth K. y Smith, S. International Relations Theory Today. Estados Unidos y Canada: Pennsylvania State University Press, 1995, p. 300.

10. Entendemos la dimensión 'económica' en el sentido de González: la intervención primaria de los otros en mis actos consiste en permitime o impedirme cl acceso a las cosas. Op. cit., p. 640 y Filosofía social, Apuntes de clase, ciclo 01/96, Universidad Centroamericana José Simeón Cañas.

11. UNRISD, Estados de desorden. Los efectos sociales de la globalización. Rcino Unido, Instiluto de Investigaciones de las Naciones Unidas para el Desartollo Social, UNRISD, 1995, p. 90.

12. Abbagnano, N. Diccionario de filosofla. México: Fondo de Cultura Económica, 1994, p. 448-451.

13. González, A. Filosofía social, Apuntes de clasc, ciclo 01/96, Universidad Centroamcricana José Simeón Cañas.

14. Pricto, F. Historia de las ideas y de las formas pollticas. Volumen III, parte 1. (Edad Moderna). Madrid: Unión Edilorial, 1990.

15. lbid, p. 44.

16. Kennedy, P. Hacia el siglo XXI. Barcelona: Plaza \& Janćs Editores, 1993.

17. Prieto, op. cit., p. 48.

18. Kennedy, op. cit., p. 160. 
19. Prieto op. cit., 57

20. Deutsch, $\mathrm{K}$ W. Las naciones en crisis. Mérico: Fondo de Cultura Economica, 1981, pp. 360-362.

21. González, "Orden mundial y liberación.", pp. 637-638. Explica el ocultamiento de vínculos y el doble criterio ético del Estado nacional.

22. González, "Orden mundial y liberación", p. 644.

23. Deutsch, op. cit., p. 362.

24. Ver González, "Orden mundial y liberación", p. 632 en adelante. 